\title{
CHARACTERIZATION OF PHENOLIC COMPOUNDS IN OLIVE STONES OF THREE MOROCCAN VARIETIES
}

\author{
Mustapha Elbir ${ }^{1}$, Nour Eddine Es-Safi ${ }^{2, \uparrow}$, Abdelatif Amhoud $^{1}$, Mohamed Mbarki $^{1}$
}

\begin{abstract}
Phenolic compounds have a fundamental importance in the nutritional and sensorial characteristics of olive. In this study phenolic compounds extracted from olive fruit stones of three Moroccan registered cultivars were analyzed. The obtained results showed that the total amount of phenolic compounds varied according to the olive variety. The stones of the Moroccan Picholine variety were the richest in total phenolic compounds (11,32 $\mathrm{mg}$ of gallic acid equivalent (GAE)/g of dry weight (DW)) followed by Haouzia (4,55 mg GAE/g DW) and Menara (3,56 mg GAE/g DW). The qualitative analysis showed that the analyzed extracts were predominated by nuzhenide and its derivatives. Thus nuzhenide was observed among the major compound in the three studied cultivars. Its mono, di and tri 11-methyl oleoside adducts were also detected. Various compounds with the same molecular weight values and corresponding to nuzhenide or its derivatives were detected indicating the presence of various isomers.
\end{abstract}

Keywords: LC-DAD-ESI/MS analysis, nuzhenide derivatives, Olea europaea, olive stones, phenolic compounds, total phenols.

\section{INTRODUCTION}

The olive tree (Olea europaea) belongs to the genus Olea of the Oleaceae family. Several species within the family provide commercial products such as food, lumber, cosmetics, and medicinal products. In the olive fruit, a wide range of phenolic structures has been reported including simple phenolic acids such as coumaric acid derivatives (Romani et al. 1999), phenolic glucosides, phenolic oleosides and flavonoids (Ragazzi et al. 1973, Vazquez et al. 1974, Vlahov 1992). Olive seeds and husks contain relatively few phenolic species, but encompass simple phenolics including tyrosol and caffeic acid, in conjunction with flavonoids and secoiridoids (Maestro-Durán et al. 1994, Servili et al. 1999). The olive stones and seeds are an important byproduct generated in the olive oil extraction and pitted table olive industries. A recent study has shown the possibility to use olive stones in particle board panels (El Bir et al. 2012). As a lignocellulosic material, the hemicellulose, cellulose and lignin are the main components of olive stone as well as protein, fat, free sugars and polyols (Fernández-Bolãnos et al. 1999, Fernández-Bolãnos et al. 2001, Rodríguez et al. 2008, Román et al. 2008).

\footnotetext{
I Transdisciplinary Team of Analytical Science for Sustainable Development, Department of Chemistry and Environment, Faculty of Science and Technologies, University of Sultan Moulay Slimane, Beni Mellal-Morocco.

${ }^{2}$ Team of Organic Chemistry and Physico-Chemical Studies. Mohammed V University of Rabat, Ecole Normale Supérieure, Rabat, Morocco.

- Corresponding author: nouressafi@yahoo.fr

Received: 20.03.2014 Accepted: 17.09.2014
} 
Phenolic compounds have also been identified in olive fruits and olive by-products (Montedoro et al. 1993, Shahidi and Naczk 2004). Olive oil contains $2 \%$ of the total phenolic content of whole olive fruits, while the remaining $98 \%$ is present in olive mill waste (Rodis et al. 2002). Olive fruits are considered as a rich source of phenolic compounds with a wide array of biological activities (Obied et al. 2005).

The phenolic compounds in olives are recognized as potentially bioactive products and may have antioxidant and therapeutic properties that produce anti-cancer, anti-viral, anti-inflammatory, hypolipidaemic and hypoglycaemic effects (Obied et al. 2005). To date, three aspects of antioxidant activity have been evaluated in olive cakes; antioxidant potency (Ranalli et al. 2003, Shahidi and Naczk 2004), anti-radical activities and radical scavenging activities (Lesage-Meessen et al. 2001, Shahidi and Naczk 2004). However, little information has been reported on the recovery of phenolic compounds from olive cake as a potential source of bioactive compounds for the pharmaceutical and nutraceutical industries (Rodis et al. 2002).

The phenolic content of olive pulp has been studied more extensively than any other olive plant tissue and has been thoroughly reviewed (Ryan et al. 1999, Ryan and Robards 1998). The main phenolic compounds in olive fruit are oleuropein and ligstroside, two glucosides of elenolic acid with 2-(3,4-dihydroxyphenyl) ethanol (hydroxytyrosol) and 2-(4-hydroxyphenyl) ethanol (tyrosol), respectively. Servili characterized maturation-induced changes in the phenolic content of the complete olive fruit, encompassing peel, pulp, and seeds in three different olive cultivars (Servili et al. 1999). Nuzhenide was detected in the olive seeds of all different varieties and at all stages of maturation. Luteolin glucoside and rutin were detected only in olive peel, whereas verbascoside, oleuropein, and demethyloleuropein were found in all three olive matrices. The concentration of the latter two phenolics was greatest in olive pulp. Similarly, Rovellini et al. 1997, have analysed the flavonoid composition of fruit, husks, and leaves plus olive oil.

The amount and type of phenolic compounds in olive depend obviously on the cultivar and maturity of the fruit, climatic conditions, storage time and processing technique (Fiorentino et al. 2003). There are many different procedures for analyzing phenolic substances, but few are used in olive analysis except for anthocyanin or color measures. HPLC methods that give specific information on individual substances are becoming more common as the significance of particular phenolic substances becomes better understood.

In Morocco, olive tree is of great interest and is cultivated in many parts of the country. The production of olive fruits is around 770000 tons and the cultivated areas are around 550000 hectares. Oil production amounted to 95300 tons corresponding to 3,3\% of the oil world production. While some studies have been made on the phytochemical composition of Moroccan varieties olive oil, to the best of our knowledge, there is no report on the phytochemical olive stones from cultivars growing in Morocco. This work was carried out on three olive stones varieties (Picholine, Haouzia and Menara). The main objectives of this study were the extraction of phenolic compounds, their quantification and the identification of the major phenolic compounds through the use of LC-MS analysis technique. 


\section{MATERIALS AND METHODS}

\section{Plant materials}

The study was conducted on three olive fruits varieties; Picholine, Menara and Haouzia. The studied samples were from Beni Mellal (Picholine) and Marrakech (Menara and Haouzia) regions. The olive fruits were harvested during 2010. For each variety, a representative sample of $2 \mathrm{~kg}$ of olive fruits has been taken.

\section{Samples Preparations}

For each variety, the harvested olive fruits $(2 \mathrm{~kg})$ were boiled in water for 8 minutes, and pulped by manual crushing. The obtained olive stones were then air dried on paper towels during 2 to 4 days. After drying, they were reduced to a fine powder using a knife mill "Retsch SK1" prior to extraction and analysis.

\section{Extraction conditions}

Phenolic compounds were extracted through solid-liquid extraction using a Soxhlet apparatus. Olive stone powder $(60 \mathrm{~g})$ was first extracted with hexane (5 hours) to remove lipids and then with acetone (5 hours) and with ethanol (5 hours).

Ultrasound extraction technique was used for polyphenols extraction using a Jeulin ultrasonic water bath (Jeulin, Evreux Cedex, France). In this case, dried olive matter ( $0,25 \mathrm{~g}$ of stone) was extracted with methanol/water $(50: 50 \mathrm{v} / \mathrm{v} ; 5 \mathrm{~mL})$ using an Ultra sound apparatus. The solution was left to stand for 10 min at ambient temperature and filtered and then stored in a refrigerator until quantitative analysis and HPLC-DAD and ESI-MS analysis.

\section{Estimation of Total Phenols}

Total phenolic compounds content in each extract was determined using the Folin-Ciocalteu method (Singleton and Rossi 1965). A 2,5 $\mathrm{ml}$ portion of Folin-Ciocalteu reagent and $2 \mathrm{ml}$ of a sodium carbonate solution $(75 \mathrm{~g} / \mathrm{l})$ were added to $0,5 \mathrm{ml}$ of each extract. The assay tubes were kept $5 \mathrm{~min}$ in a water bath at $50^{\circ} \mathrm{C}$ and then transferred to cold water. The mixture was centrifuged and the absorbance was measured at $760 \mathrm{~nm}$ using a Jasco V-360 spectrophotometer (Jasco, Tokyo, Japan). Contents of total phenolic compounds were expressed as gallic acid equivalents in milligrams per gram dry weight (mg GAE/g, DW). A calibration curve with equation: $y=0,0021 x+0,0015\left(r^{2}=0,99\right)$ was constructed using gallic acid solutions within the range $10-100 \mathrm{mg} / \mathrm{l}$. The results were averages of triplicate analyses.

\section{HPLC-DAD-MS Analysis}

The phenolic compounds were analyzed on a HPLC-MS system consisting of a quaternary solvent delivery pump (Surveyor MS, Thermo-Finnigan, USA) connected to a diode array detector (Surveyor PDA plus, Thermo-Finnigan, USA) and a LCQ Advantage MAX ion trap mass spectrometer (Thermo Scientific, Bremen, Germany), equipped with an atmospheric pressure ionization interface and operated in ESI negative and positive ion modes. The LC separation was conducted on a C18 LichroCART (250 $\mathrm{mm} \times 4,6 \mathrm{~mm}$ ) column (Merck, Germany). Separation was achieved using solvent $\mathrm{A}\left(\mathrm{H}_{2} \mathrm{O} / \mathrm{CH}_{3} \mathrm{COOH}\right.$ : 99/1) and solvent $\mathrm{B}\left(\mathrm{MeOH} / \mathrm{CH}_{3} \mathrm{CN} / \mathrm{CH}_{3} \mathrm{COOH}: 89,5 / 9,5 / 1\right)$. The used elution gradient $(1 \mathrm{ml} / \mathrm{min}$ flow rate) started from $10 \%$ to $30 \% \mathrm{~B}$ in $10 \mathrm{~min}$, isocratic during $5 \mathrm{~min}$, from 30 to $40 \% \mathrm{~B}$ in $10 \mathrm{~min}$, then to $50 \% \mathrm{~B}$ in $15 \mathrm{~min}$, from 50 to $70 \% \mathrm{~B}$ in $10 \mathrm{~min}$ and to $100 \% \mathrm{~B}$ in $10 \mathrm{~min}$ following by a washing and re-equilibrating of the colum. For the mass spectrometer, the spray voltage was $5 \mathrm{kV}$, and the temperature of the heated capillary was set to $300{ }^{\circ} \mathrm{C}$. The flow rates for sheath gas, auxiliary gas and sweep gas were set to 40,10 and 10 arbitrary units $\mathrm{min}^{-1}$, respectively. The capillary voltage was $36 \mathrm{~V}$, the split lens was $-44 \mathrm{~V}$, and the front lens was $-3,25 \mathrm{~V}$. The obtained results were processed using the XCALIBUR software program. 


\section{RESULTS AND DISCUSSION}

\section{Extraction and quantitative analysis of total phenolic compounds in olive stones}

After solid liquid extraction, the levels of total phenolic compounds were measured by FolinCiocalteu method using gallic acid as standard. The obtained results (Table 1) showed that the total phenolic compounds contents in the olive stones of the three studied varieties were 11,32 mg GAE/g (Picholine variety); 4,55 mg GAE/g (Haouzia variety) and 3,56 mg GAE/g (Menara variety). The results showed thus that Picholine variety produces olive with the highest amounts of phenolic compounds, while Menara was the poorest one.

Table 1. Polyphenol contents of the studied olive stones varieties (in g GAE/g DM).

\begin{tabular}{|l|c|c|c|c|}
\hline & \multicolumn{3}{|c|}{ Soxhlet Extraction } & Ultrasound Extraction \\
\hline Variety & Ethanol & Acetone & Total & MeOH/Water \\
\hline Picholine & 3,07 & 8,25 & 11,32 & 11,50 \\
\hline Menara & 1,86 & 1,70 & 3,56 & 4,0 \\
\hline Haouzia & 2,15 & 2,40 & 4,55 & 4,75 \\
\hline
\end{tabular}

Comparison between the classical extraction technique achieved through soxhlet apparatus and that assisted by ultrasound, the obtained results showed that the total phenolic compounds obtained through the two techniques are slightly similar with the difference that the second method was used during few minutes compared to the first one where hours are necessary for the extraction of the same amount of phenolic compounds.

The literature reports a content of total phenolic compounds in olive stones around $1 \mathrm{mg} / \mathrm{g}$ which differs from the data reported in this study (Heredia et al. 1987, Ghanbari et al. 2012). The observed differences could obviously be attributed to the type of the cultivar, geographical origin of the fruits, degree of maturity and the storage conditions but could also be due to the extraction protocols and analytic assays.

As indicated above, the olive stones constitute one of the byproducts in table olive oil industry. The obtained results showed that, in addition to their indicated above uses, olive stones could be considered as an important source of bioactive phenolic compounds. In light of the obtained results, it would seem possible to use table olive stones as a source of natural antioxidants in foods, cosmetics or pharmaceutical products, thus contributing to diminishing the environmental impact of table olive by-product and to its revalorization.

\section{Analysis and characterization of olive stone phenolic compounds}

After quantitative analysis, the three studied olive stone samples (Picholine, Haouzia and Menara) were analyzed by HPLC coupled to both diode array and mass spectrometry detectors. The latter was used with electrospray ionization source in both negative and positive ion modes. ESI LC-MS analysis was performed using cone voltage providing useful additional fragmentation data. 
A representative UV and total ion current (TIC) chromatograms are shown in Figure 1. The similarity between the total ion chromatogram (TIC) obtained and its UV analogue indicated that the detected compounds in the stone extracts are ionizable in the experimental used conditions. The HPLC separation profile revealed a high complexity in the stone phenolic composition as demonstrated by the presence of various chromatographic peaks.

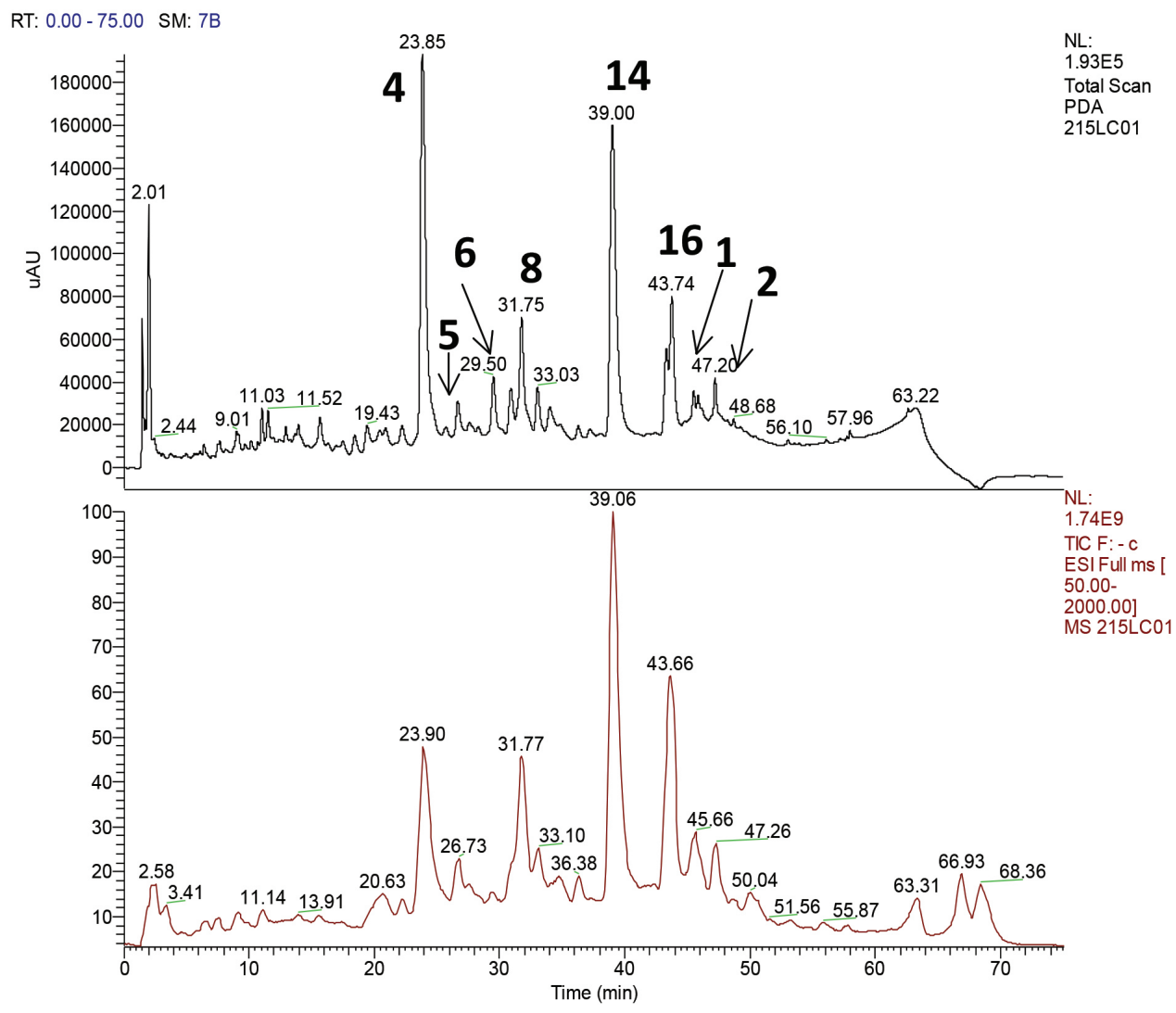

Figure 1. HPLC chromatograms of olive stone extract acquired through PDA detector (top) and ESI/ MS detector (bottom). Identified compounds are listed in table 2.

The structures of the tentatively identified compounds representing the major detected peaks and summarizing the obtained data for each of the detected chromatographic peak are discussed below. Compounds identification was based on retention data and ESI mass spectra and by comparison with literature data (Servili et al. 1999, Silva 2006, Duran et al. 1994, Luaces et al. 2007, Owen et al. 2003, Silva et al. 2010, Cardoso et al. 2005, Angelino et al. 2011, Rodriguez et al. 2008, Rodriguez et al. 2008, Obied et al. 2007, Lozano-Sanchez et al. 2011). The identification of the detected compounds was based on the search of the main molecular ions detected in the both used polarities and also on some of the useful observed fragmentations. ESI LC-MS was performed using cone voltages, in both positive and negative ion modes, with the higher cone voltage providing additional fragmentation data. Compounds with a presence listed as tentative in table 2 were restricted to those instances in which both $[\mathrm{M}+\mathrm{H}]^{+}$ and $[\mathrm{M}-\mathrm{H}]$ - ions were detected in positive and negative ion ESI, respectively. Among the observed peaks, some were too small to allow structural analyses. The presence of several adducts was observed: acetate in negative ionization mode, due to the presence of acetic acid in the mobile phase, and sodium adducts in positive ion mode. 
Table 2. Tentative identification of olive fruit stones phenolic compound.

\begin{tabular}{|c|c|c|c|c|c|}
\hline $\mathrm{N}^{\circ}$ & $\begin{array}{c}\operatorname{tr} \\
(\min .)\end{array}$ & MS- & MS+ & $\begin{array}{c}\text { Molecular } \\
\text { weight }\end{array}$ & $\begin{array}{c}\text { Tentative } \\
\text { identification }\end{array}$ \\
\hline 1 & 9,01 & 625,565 & & 566 & $\begin{array}{c}\text { Elenolic acid } \\
\text { diglucoside }\end{array}$ \\
\hline 2 & 11,03 & $807,463,241$ & & 404 & $\begin{array}{l}\text { Elenolic acid } \\
\text { glucoside }\end{array}$ \\
\hline 3 & 15,67 & 417,255 & & 418 & $\begin{array}{l}\text { Oleoside dimethyl } \\
\text { ester }\end{array}$ \\
\hline 4 & 23,85 & $1371,745,685,523$ & 709,687 & 686 & nuzhenide \\
\hline 5 & 26,67 & $1371,745,685,523$ & 709,687 & 686 & nuzhenide isomer \\
\hline 6 & 29,50 & 533 & 535 & 534 & unknown \\
\hline 7 & 30,90 & $1131,1071,685,523$ & $\begin{array}{c}1095 \\
709 \\
\end{array}$ & 1072 & $\begin{array}{l}\text { nuzhenide 11- } \\
\text { methyl oleoside }\end{array}$ \\
\hline 8 & 31,75 & $1131,1071,685,523$ & 1095 & 1072 & nuzhenide 11- \\
\hline & & & 709 & & methyl oleoside \\
\hline 9 & 33,03 & 523 & & 524 & Ligstroside \\
\hline 10 & 34,02 & $1131,1071,685,523$ & $\begin{array}{c}1095 \\
709\end{array}$ & 1072 & $\begin{array}{l}\text { nuzhenide 11- } \\
\text { methyl oleoside }\end{array}$ \\
\hline 11 & 34,04 & $1131,1071,685,523$ & $\begin{array}{c}1095 \\
709\end{array}$ & 1072 & $\begin{array}{l}\text { nuzhenide 11- } \\
\text { methyl oleoside }\end{array}$ \\
\hline 12 & 36,28 & $1131,1071,685,523$ & $\begin{array}{c}1095 \\
709\end{array}$ & 1072 & $\begin{array}{l}\text { nuzhenide 11- } \\
\text { methyl oleoside }\end{array}$ \\
\hline 13 & 37,22 & $1131,1071,685,523$ & $\begin{array}{c}1095 \\
709 \\
\end{array}$ & 1072 & $\begin{array}{l}\text { nuzhenide 11- } \\
\text { methyl oleoside }\end{array}$ \\
\hline 14 & 39 & $1131,1071,685,523$ & $\begin{array}{c}1095 \\
709\end{array}$ & 1072 & $\begin{array}{l}\text { nuzhenide 11- } \\
\text { methyl oleoside }\end{array}$ \\
\hline 15 & 43,31 & 1457,685 & 1481 & 1458 & $\begin{array}{l}\text { nuzhenide di (11- } \\
\text { methyl oleoside) }\end{array}$ \\
\hline 16 & 43,74 & 1457,685 & 1481 & 1458 & $\begin{array}{l}\text { nuzhenide di (11- } \\
\text { methyl oleoside) }\end{array}$ \\
\hline 17 & 45,50 & $1843,1131,1071$ & $\begin{array}{l}1867 \\
1095\end{array}$ & 1844 & $\begin{array}{c}\text { nuzhenide tri (11- } \\
\text { methyl oleoside) }\end{array}$ \\
\hline 18 & 45,84 & $1843,1131,1071$ & $\begin{array}{l}1867 \\
1095\end{array}$ & 1844 & $\begin{array}{c}\text { nuzhenide tri (11- } \\
\text { methyl oleoside) }\end{array}$ \\
\hline 19 & 46,12 & $1843,1131,1071$ & $\begin{array}{l}1867 \\
1095\end{array}$ & 1844 & $\begin{array}{c}\text { nuzhenide tri (11- } \\
\text { methyl oleoside) }\end{array}$ \\
\hline 20 & 47,20 & 1457,685 & 1481 & 1458 & $\begin{array}{c}\text { nuzhenide di (11- } \\
\text { methyl oleoside) }\end{array}$ \\
\hline 21 & 48,68 & 1457,685 & 1481 & 1458 & $\begin{array}{c}\text { nuzhenide di (11- } \\
\text { methyl oleoside) }\end{array}$ \\
\hline
\end{tabular}

The compound 4 with the retention time 23,85 min gives in negative ion mode a mass spectrum with intense peak signals at $\mathrm{m} / \mathrm{z} 685$ and 1371 corresponding respectively to $[\mathrm{M}-\mathrm{H}]^{-}$and $[2 \mathrm{M}-\mathrm{H}]^{-}$of nuzhenide. This was also confirmed by the appearance of a signal ion at $\mathrm{m} / \mathrm{z} 745$, detected in full MS spectrum, which is an acetic acid adduct $\left[\mathrm{M}+\mathrm{CH}_{3} \mathrm{COO}\right]$ - of nuzhenide. Among the other fragment ion peak signals that observed at $\mathrm{m} / \mathrm{z} 523$ in agreement with the structure of nuzhenide. This ion corresponds to the loss of 162 mass units was formed through the release of the glucoside moiety yielding the aglycon part with a $m / z$ value of 523 . 
When the analysis was performed in the positive ion mode, the protonated ion signal was observed with a weak intensity at $\mathrm{m} / \mathrm{z}$ 687, while the most intense peak signal in the obtained mass spectrum was observed at $\mathrm{m} / \mathrm{z} 709$ corresponding to the sodiated adduct of $[\mathrm{M}+\mathrm{Na}]^{+}$of nuzhenide. These data confirmed thus that this compound correspond to nuzhenide which has already been identified in Olea europaea seeds (Servili et al. 1999).

Compound 5 which eluted at 26,73 min showed mass spectrum similar to that of compound 4 suggesting that it was an isomer of nuzhenide. The presence of this compound at several retention times with the same pattern fragmentation has already been reported in olive fruits. This was also observed in the literature for Ligustrum lucidum (He et al. 2001) and Syringa reticulate (Koichi et al. 2002).

Compound 6 eluted at 29,50 min. Its mass spectra showed ion signals at $m / z 535\left([\mathrm{M}+\mathrm{H}]^{+}\right)$and 533 ([M-H] $]^{-}$indicating a molecular weight of 534. However the weak obtained mass spectra did not allow the unambiguous identification of this compound.

Compound 8 eluted at 31,75 min was identified as nuzhenide 11-methyl oleoside. Indeed the obtained results showed that this compound has a more 386 mass units than nuzhenide corresponding to an addition of one unit of 11-methyl oleoside to the latter molecule. This compound was detected in negative and positive modes. Since it has a molecular mass of 1072 the deprotonated ion $[\mathrm{M}-\mathrm{H}]^{-}$in the mass spectrum in negative mode was observed at $\mathrm{m} / z 1071$ and the acetate adduct was also observed at $\mathrm{m} / \mathrm{z} 1131$. Other fragment signals were observed at $\mathrm{m} / \mathrm{z} 685,523$ corresponding to the loss of the 11-methyl oleoside unit yielding the deprotonated nuzhenide fragment while the further loss of the glucose moiety yields the fragment detected at $m / z 523$.

The positive ionization mode enabled the detection of the ion $\mathrm{m} / \mathrm{z} 1095$, corresponding to the sodium adduct of the compound. The fragment corresponding to the loss of the 11-methyl oleoside unit was also observed at $m / z 709$ corresponding to the sodiated nuzhenide fragment. Nuzhenide oleoside was identified by Maestro-Durán in olive seeds (Durán et al. 1994).

Nuzhenide and nuzhenide 11-methyl oleoside were detected in samples and represent compounds that have already been identified in Olea europaea L. seeds.

Compound 14 which eluted at 39 min showed MS spectra similar to that of compound 8 . The detection of nuzhenide 11-methyl oleoside at different retention times indicated the presence of isomers.

The MS spectrum of compound 16 eluted at $43,74 \mathrm{~min}$. showed a signal at $\mathrm{m} / \mathrm{z}$ located at $1457 \mathrm{in}$ the negative ion mode showing a 386 amu compared to compounds 8 and 14 which is in agreement with an additional 11-methyl oleoside unit. This compound was thus concluded to be the deprotonated ion of nuzhenide di (11-methyl oleoside) compound. The corresponding sodiated adduct was observed at $\mathrm{m} / \mathrm{z}$ 1481 in the positive ion mode which was observed as the parent ion. Among the observed fragment, that obtained through successive loss of two methyloleoside units giving a nuzhenide fragment at $\mathrm{m} / \mathrm{z}$ 685 in the negative ion mode.

The MS spectrum of compound 17 eluted at 45,50 min. showed a signal at $\mathrm{m} / \mathrm{z}$ located at 1843 in the negative ion mode. This corresponds to the deprotonated ion of nuzhenide tri (11-methyl oleoside) compound. Other fragments were observed at 1071 and 1131 corresponding respectively to the deprotonated and the acetate adducts of the ion obtained through the successive loss of two methyl oleoside units. 
The MS spectrum of this compound obtained in the positive ion mode was characterized by the presence of a signal at $\mathrm{m} / \mathrm{z} 1867$ corresponding to the sodiated product ion of nuzhenide tri (11-methyl oleoside) molecule. Among the observed fragments, the ion obtained through the loss of two methyl oleoside units yielding an ion fragment located at $\mathrm{m} / \mathrm{z} 1095$.

The compound 2 that eluted at 11,03 min showed an intense ion at $\mathrm{m} / \mathrm{z} 403$ corresponding to a molecular weight of 404 . This was confirmed by the presence of signals at $m / z 463$ and 807 corresponding respectively to the ions $\left[\mathrm{M}+\mathrm{CH}_{3} \mathrm{COOH}-\mathrm{H}\right]^{-}$and $[2 \mathrm{M}-\mathrm{H}]^{-}$. A fragment corresponding to the loss of a glucoside moiety was observed at $\mathrm{m} / \mathrm{z} 241$. The observed data are characteristic of the product described in literature for 11-methyloleoside (elenolic acid glucoside), a degradation product of oleuropein which accumulates during ripening. This compound has been already identified in olives (Cardoso et al. 2005, Ryan et al. 1999, Ryan et al. 2002), such as in other species belonging to the Oleaceae family (SolerRivas et al. 2000).

The compound 1 was eluted at 9,12 min presents a mass spectrum with a peak signal at $\mathrm{m} / \mathrm{z} 565$ corresponding to its deprotonated molecular ion. This was confirmed by the presence of a signal at $\mathrm{m} / \mathrm{z}$ 625 corresponding to $\left[\mathrm{M}+\mathrm{CH}_{3} \mathrm{COOH}-\mathrm{H}\right]$ ' ion. This is in favor of a product with a molecular weight of 566 which presents an additional hexose moiety compared to elenolic acid glucoside which was eluted at $11,03 \mathrm{~min}$.

In addition to the products described above which appeared as major compounds in the obtained chromatographic profiles, other minor products were also observed. This is the case of ligstroside (compound 9) eluting at 33,03 min. and showing a MS spectrum with a signal at $\mathrm{m} / \mathrm{z} 523$ in the negative ion mode corresponding to the deprotonated ion. Another compound 3 was eluted at 15,5 min. Its mass spectrum showed a peak signal at $\mathrm{m} / \mathrm{z} 417$ corresponding to that of oleoside dimethyl ester. A neutral loss of $162 \mathrm{amu}$ was observed giving a peak signal at $\mathrm{m} / \mathrm{z} 255$ corresponding to the loss of the hexose moiety.

The results obtained above showed that olive fruit stones contain a variety of phenolic compounds that are potent antioxidants. The positive effect of olives and olive-derived products consumption on human health is well documented by a large number of epidemiological studies (Owen et al. 2000, Visioli et al. 2000, 1999). The presence of various phenolic compounds in olive stones open new perspectives for their important role in the chemical, organoleptic and nutritional properties of the virgin olive oil and the table olives. Indeed olive stones could be used within olive oil industry to enhance the phenolic composition of olive oils (Patumi et al. 2003).

The obtained results showed that the whole olive stone is a rich source of bioactive compounds. These potentially valuable compounds were nuzhenide and its mono, di and tri-oleoside derivatives. Other minor compounds such as salidroside, ligstroside, elenolic acid glucosides, oleoside dimethyl ester were also detected. Other compounds such as flavonoid derivatives, already identified in Olea europaea stones, were not detected in the three varieties analyzed. The observed differences could obviously be attributed to the type of the variety or the plant environment such as geographical origin of the fruits, degree of maturity and the storage conditions but could also be due to the extraction and analysis used procedures.

\section{Proportion of phenolic compounds}

The phenolic compounds tentatively identified above were analyzed in the stone extracts of the three studied olive varieties. The chromatographic profiles obtained for the extracts of olive stones of three olive tree cultivars were compared and the obtained results are summarized in table 3 . The phenolic extracts from the three studied varieties displayed similar qualitative profiles and differed in their proportion as demonstrated by the differences observed in the area of peaks with the same retention time. 
Table 3. Proportion of phenolic compounds of the extracts obtained from the three studied olive fruits stones cultivars (results are given in \%).

\begin{tabular}{|c|c|c|c|c|c|}
\hline $\mathrm{N}^{\circ}$ & $\begin{array}{c}\operatorname{tr} \\
(\min .)\end{array}$ & MS- & MS+ & $\begin{array}{l}\text { Molecular } \\
\text { weight }\end{array}$ & $\begin{array}{c}\text { Tentative } \\
\text { identification }\end{array}$ \\
\hline 1 & 9,01 & 625,565 & & 566 & $\begin{array}{l}\text { Elenolic acid } \\
\text { diglucoside }\end{array}$ \\
\hline 2 & 11,03 & $807,463,241$ & & 404 & $\begin{array}{l}\text { Elenolic acid } \\
\text { glucoside }\end{array}$ \\
\hline 3 & 15,67 & 417,255 & & 418 & $\begin{array}{l}\text { Oleoside dimethyl } \\
\text { ester }\end{array}$ \\
\hline 4 & 23,85 & $1371,745,685,523$ & 709,687 & 686 & nuzhenide \\
\hline 5 & 26,67 & $1371,745,685,523$ & 709,687 & 686 & nuzhenide isomer \\
\hline 6 & 29,50 & 533 & 535 & 534 & unknown \\
\hline 7 & 30,90 & $1131,1071,685,523$ & $\begin{array}{c}1095 \\
709\end{array}$ & 1072 & $\begin{array}{l}\text { nuzhenide 11- } \\
\text { methyl oleoside }\end{array}$ \\
\hline 8 & 31,75 & $1131,1071,685,523$ & 1095 & 1072 & nuzhenide 11- \\
\hline & & & 709 & & methyl oleoside \\
\hline 9 & 33,03 & 523 & & 524 & Ligstroside \\
\hline 10 & 34,02 & $1131,1071,685,523$ & $\begin{array}{c}1095 \\
709\end{array}$ & 1072 & $\begin{array}{l}\text { nuzhenide 11- } \\
\text { methyl oleoside }\end{array}$ \\
\hline 11 & 34,04 & $1131,1071,685,523$ & $\begin{array}{c}1095 \\
709 \\
\end{array}$ & 1072 & $\begin{array}{l}\text { nuzhenide 11- } \\
\text { methyl oleoside }\end{array}$ \\
\hline 12 & 36,28 & $1131,1071,685,523$ & $\begin{array}{c}1095 \\
709\end{array}$ & 1072 & $\begin{array}{l}\text { nuzhenide 11- } \\
\text { methyl oleoside }\end{array}$ \\
\hline 13 & 37,22 & $1131,1071,685,523$ & $\begin{array}{c}1095 \\
709\end{array}$ & 1072 & $\begin{array}{l}\text { nuzhenide 11- } \\
\text { methyl oleoside }\end{array}$ \\
\hline 14 & 39 & $1131,1071,685,523$ & $\begin{array}{c}1095 \\
709\end{array}$ & 1072 & $\begin{array}{l}\text { nuzhenide 11- } \\
\text { methyl oleoside }\end{array}$ \\
\hline 15 & 43,31 & 1457,685 & 1481 & 1458 & $\begin{array}{c}\text { nuzhenide di (11- } \\
\text { methyl oleoside) }\end{array}$ \\
\hline 16 & 43,74 & 1457,685 & 1481 & 1458 & $\begin{array}{l}\text { nuzhenide di (11- } \\
\text { methyl oleoside) }\end{array}$ \\
\hline 17 & 45,50 & $1843,1131,1071$ & $\begin{array}{l}1867 \\
1095\end{array}$ & 1844 & $\begin{array}{c}\text { nuzhenide tri (11- } \\
\text { methyl oleoside) }\end{array}$ \\
\hline 18 & 45,84 & $1843,1131,1071$ & $\begin{array}{l}1867 \\
1095 \\
\end{array}$ & 1844 & $\begin{array}{c}\text { nuzhenide tri (11- } \\
\text { methyl oleoside) }\end{array}$ \\
\hline 19 & 46,12 & $1843,1131,1071$ & $\begin{array}{l}1867 \\
1095\end{array}$ & 1844 & $\begin{array}{c}\text { nuzhenide tri (11- } \\
\text { methyl oleoside) }\end{array}$ \\
\hline 20 & 47,20 & 1457,685 & 1481 & 1458 & $\begin{array}{l}\text { nuzhenide di (11- } \\
\text { methyl oleoside) }\end{array}$ \\
\hline 21 & 48,68 & 1457,685 & 1481 & 1458 & $\begin{array}{l}\text { nuzhenide di (11- } \\
\text { methyl oleoside) }\end{array}$ \\
\hline
\end{tabular}

The stone extract of the picholine variety showed, significantly, the highest values for the all detected compounds and the Haouzia variety presented lower values. The chemical compositions of the three studied varieties were dominated by nuzhenide and its 11-methyl oleoside derivatives. The total percentage of these compounds were 23,05 (Haouzia); 38,65 (Menara) and 48,32 (Picholine). 
Thus, the major compound in the stone extract of the picholine variety was nuzhenide $(19,45 \%)$ followed by one of its 11-methyl oleoside $(17,84 \%)$. The total nuzhenide derivatives were $27,64 \%$ (mono oleoside); 12,63 (di oleoside) and 4,5 (tri oleoside).

The chromatographic profile of the stone extract of Menara variety was similar to that of Picholine with the difference that the mono oleoside derivative was the major compound $(12,71 \%)$ followed by nuzhenide (10,01\%). The total nuzhenide derivatives were 27,32\% (mono oleoside); 10,38 (di oleoside) and 4,11 (tri oleoside).

In the case of the stone extracted from Haouzia variety, many compounds with small peaks area were observed from which some were unidentified derivatives. Nuzhenide was present with only 6,02 $\%$ while its mono oleoside derivatives were the major compounds $(17,03 \%)$. The di and tri oleoside nuzhenide derivatives were observed with 5,29 and 0,93\% respectively. The total peak area $(42,35 \%)$ of the identified compounds of this variety extract is relatively small compared to that of Menara $(63,36 \%)$ and Picholine $(71,28 \%)$ varieties. This showed that Haouzia variety contains other unknown compounds with a small proportions compared to the two other varieties,

The data obtained that the phenolic compositions of the olive fruit stones were predominated by nuzhenide and its derivatives. High levels of nuzhenide derivatives were indeed detected in the seed extracts of the three cultivars analysed. These data confirmed the previously reported data indicating that nuzhenide is located mainly in olive seed (Servili et al. 1999). 


\section{CONCLUSIONS}

This investigation showed that the stones of the studied varieties had an appreciable amount of bioactive compounds. The chemical composition varied slightly among the three studied varieties. The LC/ESI-MS indicated the presence of various compounds and allowed the identification of nuzhenide derivatives among the major compounds in the three studied varieties.

The MS analysis of the detected compounds showed that the analyzed extracts were predominated by nuzhenide and its derivatives. Thus nuzhenide was observed among the major compound in the three studied cultivars. Its mono, di and tri 11-methyl oleoside adducts were also detected. Various compounds with the same molecular weight values and corresponding to nuzhenide or its derivatives were detected indicating the presence of various isomers. Among the three studied samples, variation in some individual compounds was observed but the three cultivars were qualitatively similar.

This study showed thus that olive stones are not waste worthless, they should be considered as an interesting source of potent antioxidants such phenolic compounds. This is of great interest for promoting the olive culture and better exploitation of the olive fruit stones which are considered as a by-product from the table olive canning industry with some residual olive flesh.

\section{REFERENCES}

Angelino, D.; Gennari, L.; Blasa, M.; Selvaggini, R.; Urbani, S.; Esposto, S.; Servili, M.; Ninfali, P. 2011. Chemical and Cellular Antioxidant Activity of Phytochemicals Purified from Olive Mill Waste Waters. Journal of Agricultural and Food Chemistry 59: 2011-2018.

Cardoso, S.M.; Guyot, S.; Marnet, N.; Lopes-da-Silva, J.A.; Renard, C.; Coimbra, M.A. 2005. Characterisation of phenolic extracts from olive pulp and olive pomace by electrospray mass spectrometry. Journal of the Science of Food and Agriculture 85: 21-32.

Durán, N.; Curotto, E.; Esposito, E.; Aguirre, C.; Nazal, A.; Angelo, R. 1994. Aspergillus sp. 2M1 Xylanase: Production, Characterization and Application in the Pulp and Paper Industry. In: Galindo E, Ramirez OT, eds. Advances in Bioprocesses Engineering. Kluwer Academic Publishers, Dordrecht, pp. 489-494.

Elbir, M.; Moubarik, A.; Rakib, E.M.; Grimi, N. ; Amhoud, A.; Miguel, G.; Hanine, H.; Artaud, J.; Vanloot, P.; Mbarki, M. 2012. Valorization of Moroccan olive stones by using it in particle board panels. Maderas. Ciencia y Tecnologia 14(3): 361-371.

Fernández-Bolãnos, J.; Felizón, B.; Heredia, A.; Rodríguez, R.; Guillén, R.; Jiménez, A. 1999. Characterization of the lignin obtained by alkaline delignification and the cellulose residue from steamexploded olive stones. Bioresource Technology 68: 121-132.

Fernández-Bolãnos, J.; Felizón, B.; Heredia, A.; Rodríguez, R.; Guillén, R.; Jiménez, A. 2001. Steam-explosion of olive stones: hemicelluloses solubilization and enhancement of enzymatic hydrolysis of cellulose. Bioresource Technology 79: 53-61.

Fiorentino, A.; Gentili, A.; Isidori, M.; Monaco, P.; Nardelli, A.; Parrella, A. 2003. Environmental effects caused by olive mill wastewaters: Toxicity comparison of low-molecular weight phenol components. Journal of Agricultural and Food Chemistry 51: 1005-1009. 
Ghanbari, R., Anwar, F.; Alkharfy, K. M.; Gilani, A. H.; Saari, N. 2012. Valuable Nutrients and Functional Bioactives in Different Parts of Olive (Olea europaea L.) A Review. International Journal of Molecular Sciences 13: 3291-3340.

He, Z.D.; But, P.P.H.; Chan, T.W.D.; Dong, H.; Xu, H.X.; Lau, C.P.; Sun, H.D. 2001. Antioxidative glucosides from the fruits of Ligustrum lucidum. Chemical and Pharmaceutical Bulletin 49: 780-784.

Heredia, A.; Guillén, R.; Fernández-Bolaños, J.; Rivas, M. 1987. Olives stones as a source of fermentable sugars. Biomass 14: 143-148.

Koichi, M.; Kaneko, A.; Hosogai, T.; Kakuda, R.; Yaoita, Y.; Kikuchi M. 2002. Studies on the constituents of Syringaspecies. X. Five new iridoid glycosides from the leaves of Syringa reticulate (Blume) Hara. Chemical and Pharmaceutical Bulletin 50: 493-497.

Lesage-Meessen, L.; Navarro, D.; Maunier, S.; Sigoillot, J. C.; Lorquin, J.; Delattre, M. 2001. Simple phenolic content in olive oil residues as a function of extraction systems. Food Chemistry 75: 501-507.

Lozano-Sanchez, J. ; Giambanelli, L. ; Quirantes-Pine, R. ; Cerretani, L. ; Bendini, A., SeguraCarretero, A. ; Fernandez-Gutierrez, A. 2011. Wastes Generated during the Storage of Extra Virgin Olive Oil as a Natural Source of Phenolic Compounds. Journal of Agricultural and Food Chemistry 59: 11491-11500.

Luaces, P.; Romero, C.; Gutierrez, F.; Sanz, C.; Perez, G. 2007. Contribution of olive seed to the phenolic profile and related quality parameters of virgin olive oil. Journal of the Science of Food and Agriculture 87: 2721-2727.

Maestro-Durán, R.; Cabello, L.R.; Gutiérrez, R. V.; Roncero, V. A. 1994. Glucósidos fenólicos amargos de las semillas del olivo (Olea europaea). Grasas y Aceites 45: 332-335.

Montedoro, G.; Servili, M.; Baldioli, M.; Selvaggini, R.; Miniati, E.; Maccioni, A. 1993. Simple and hydrolyzable compounds in virgin olive oil. III. Spectroscopic characterizations of the secoiridoid derivatives. Journal of Agricultural and Food Chemistry 41: 2228-2234.

Obied, H.K.; Allen, M.S.; Bedgood, D.R.; Prenzler, P.D.; Robards, K.; Stockmann, R. 2005. Bioactivity and analysis of biophenols recovered from olive mill waste. Journal of Agricultural and Food Chemistry 53: 823-837.

Obied, H.K.; Bedgood, D.R.; Prenzler, P.D.; Robards, K. 2007. Chemical screening of olive biophenol extracts by hyphenated liquid chromatography. Analytica Chimica Acta 603: 176-189.

Owen, R.W.; Mier, W.; Giacosa, A.; Hull, W. E.; Spiegelhalder, B.; Bartsch, H. 2000. Identification of lignans as major components in the phenolic fraction of olive oil. Clinical Chemistry 46: 976-988.

Owen, R.W.; Haubner, R.; Mier, Giacosa, A.; Hull, W.E.; Spiegelhalder, B.; Bartsch, H. 2003. Isolation, structure elucidation and antioxidant potential of the major phenolic and flavonoid compounds in brined olive drupes. Food and Chemical Toxicology 41: 703-717.

Patumi, M.; Terenziani, S.; Ridolfi, M.; Fontanazza, G. 2003. Effect of fruit stoning on olive oil quality. Journal of the American Oil Chemists'Society 80: 249-255. 
Ragazzi, E.; Veronese, G.; Guiotto, A. 1973. Demethyloleuropein, a new glycoside isolated from ripe olives. Annali di Chimica 63: 13-20.

Ranalli, A.; Lucera, L.; Contento, S. 2003. Antioxidizing potency of phenol compounds in olive oil mill wastewater. Journal of Agricultural and Food Chemistry 51: 7636-7641.

Rodis, P.S.; Karathanos, V.T.; Mantzavinou, A. 2002. Partitioning of olive oil antioxidants between oil and water phases. Journal of Agricultural and Food Chemistry 50: 596-601.

Rodríguez, G.; Lama, A.; Rodríguez, R.; Jiménez, A.; Guillén, R.; Bolanos, J.F. 2008. Olive Stone an attractive source of bioactive and valuable compounds. Bioresource Technology 99: 5261-5269.

Román, S.; González, J.F.; González-García, C.M.; Zamora, F. 2008. Control of por development during $\mathrm{CO}_{2}$ and steam activation of olive stones. Fuel Processing Technology 89: 715-720.

Romani, A.; Mulinacci, N.; Pinelli, P.; Vincieri, F.F.; Cimato, A. 1999. Polyphenolic content in five Tuscany cultivars of Olea europaea L. Journal of Agricultural and Food Chemistry 47: 964-967.

Rovellini, P.; Cortesi, N.; Fedeli, E. 1997. Analisis of flavonoids from Olea europea by HPLC-UV and HPLC-electrospray-MS. Rivista Italiana Delle Sostanze Grasse 74: 273-279.

Ryan, D.; Antolovich, M.; Herlt, T.; Prenzler, P. D.; Lavee, S.; Robards, K. 2002. Identification of phenolic compounds in tissues of the novel olive cultivar Hardy's Mammoth. Journal of Agricultural and Food Chemistry 50: 6716-6724.

Ryan, D.; Robards, K. 1998. Phenolic compounds in olives. Analyst 123: 31-44.

Ryan, D.; Robards, K.; Lavee, S. 1999. Changes in phenolic content of olive during maturation. International Journal of Food Science and Technology 34: 265-274.

Servili, M., Baldioli, M., Selvaggini, R., Macchioni, A., Montedoro, G. 1999. Phenolic compounds of olive fruit: one- and two-dimensional nuclear magnetic resonance characterization of Nuzhenide and its distribution in the constitutive parts of fruit. Journal of Agricultural and Food Chemistry 47: 12-18.

Shahidi, F.; Naczk, M. 2004. Phenolic in food and nutraceutical. Boca Raton, FL: CRC Press. 558p.

Silva, S.; Gomes, L.; Leitão, F.; Bronze, M.; Coelho, A.V.; Vilas Boas, L. 2010. Secoiridoids in olive seed: characterization of nuzhenide and 11-methyl oleosides by liquid chromatography with diode array and mass spectrometry. Grasas y Aceites 61: 157-164.

Silva, S.; Gomes, L.; Leitão, F.; Coelho, A.V.; Vilas Boas. L. 2006. Phenolic compounds and antioxidant activity of Olea europaea L. fruits and leaves. Food Science and Technology International 12: 385-396

Singleton, V.L.; Rossi, J. 1965. Colorimetry of total phenolics with phosphomolybdic phosphotungstic acid reagents. American Journal of Enology and Viticulture 16: 144-158.

Soler-Rivas, C.; Espın, J.C.; Wichers H.J. 2000. Oleuropein and related compounds. Journal of the Science of Food and Agriculture 80: 1013-1023.

Vazquez-Roncero, A.; Graciani-Constante, E.; Maestro-Duran, R. 1974. Phenolic compounds in olive fruits. I. Polyphenols in pulp. Grasas y Aceites 25: 269-279. 
Visioli, F.; Caruso, D.; Galli, C.; Viappiani, S.; Galli, G.; Sala A. 2000. Olive oils rich in natural catecholic phenols decrease isoprostane excretion in humans. Biochemical and Biophysical Research Communications 278 : 797-799.

Visioli, F.; Romani, A.; Mulinacci, N.; Zarini, S.; Conte, D.; Vincieri, F.F. ; Galli, C. 1999. Antioxidant and other biological activities of olive oil mill waste water. Journal of Agricultural and Food Chemistry 47: 3397-3401.

Vlahov, G. 1992. Flavonoids in three olive (Olea europea) fruit varieties during maturation. Journal of the Science of Food and Agriculture 58: 157-159. 